\title{
The Marginal Syllabus: \\ Educator Learning and Web Annotation Across Sociopolitical Texts and Contexts
}

\author{
Jeremiah H. Kalir \\ University of Colorado Denver, United States of America \\ Francisco Perez \\ University of Colorado Denver, United States of America
}

Preprint to appear as:

Kalir, J., \& Perez, F. (2019). The Marginal Syllabus: Educator learning and web annotation across sociopolitical texts and contexts. In A. Reid (Ed.), Marginalia in modern learning contexts. Hershey, PA: IGI Global.

Correspondence concerning this manuscript should be addressed to:

Jeremiah H. Kalir

University of Colorado Denver

School of Education and Human Development

1380 Lawrence Street, Suite 645

Denver, CO 80204

remi.kalir@ucdenver.edu

(303) 315-0034 


\title{
The Marginal Syllabus: \\ Educator Learning and Web Annotation Across Sociopolitical Texts and Contexts
}

\author{
Jeremiah H. Kalir \\ University of Colorado Denver, United States of America \\ Francisco Perez \\ University of Colorado Denver, United States of America
}

\begin{abstract}
This case study examines educator learning as mediated by open web annotation among sociopolitical texts and contexts. The chapter introduces annotation practices and conceptualizes intertextuality to describe how open web annotation creates dialogic spaces which gather together people and texts, coordinates meaning-making, and encourages political agency. This perspective on texts-as-contexts is used to present and analyze educator participation in the Marginal Syllabus, a social design experiment that leverages open web annotation to foster conversation about educational equity. One conversation from the inaugural year of the Marginal Syllabus is analyzed using mixed method approaches to data collection, analysis, and the presentation of findings. Learning analytics and discourse analysis detail how open web annotation mediated educator participation among sociopolitical texts and contexts of professional relevance. The chapter concludes by discussing open web annotation as a means of coordinating educator participation in public conversations about sociopolitical issues related to educational equity.
\end{abstract}

Keywords: Annotation, Collaboration, Dialogic Space, Discourse Analysis, Educator Learning, Equity, Hypothesis, Intertextuality, Open Learning, Open Web Annotation, Social Design Experiment 


\section{INTRODUCTION}

This chapter explores the relationship between everyday digital media practice and political agency. Specifically, we theorize such practice in reference to perspectives on intertextuality and we present a study of educators' learning as mediated by open web annotation (OWA) among sociopolitical texts and contexts. In an era when both classrooms and educational technologies are frequently a locus of surveillance and control - sites, it can be argued, where "dominant ideologies are produced" (Apple, 1995, p. 14) - we are especially concerned with participation structures that encourage political dimensions of talk (e.g., Slakmon \& Schwarz, 2017), how educators engage in such discourse, and the ways in which educator involvement in dialogic space (Wegerif, 2007) becomes relevant to classroom teaching and learning. The efforts reported in this chapter are directed to both inquiry and change; we present a case study of a social design experiment (Gutiérrez \& Vossoughi, 2010) predicated upon the need to create and maintain open learning contexts within which educators can exercise political agency through dialogue, question dominant schooling narratives, and critique inequitable educational practices. In this respect, our chapter is an attempt to work "toward understanding and acting on educational technology in terms of its complicated and often unjust connections to the larger society... to develop a more politically aware and sociologically grounded narrative of change" (Selwyn \& Facer, 2013, p. 4). We develop one such narrative of change by examining OWA as both a context for and a mediator of educator agency that is grounded in social and political contexts of education, expansive designs for professional learning, and new expressions of media practice (Kalir \& Dean, 2018).

As evidenced by historic, economic, and pedagogical analyses, the use of technologies for both formal and interest-driven learning can be perceived critically and as reflecting political interests, whether corporate or of the state (e.g., Cuban, 1986; Watters, 2016). A similar case may be made about educator professional development, which historically has been limited by atomistic and authoritative design (Webster-Wright, 2009), as well as disconnection from relevant learning activities and contexts (Hill, 2009). Amidst these conditions, digital technologies and everyday media practices have opened public, more participatory, and collaborative repertoires through which educators have begun to frequently engaging in professionally-relevant learning (Gover, 2017; Jones \& Dexter, 2014; Pew Internet \& American Life Project, 2013). At times both promising and also problematic, efforts like Twitter chats (Carpenter \& Krutka, 2015; Visser, Evering, \& Barrett, 2014), EdCamps (Carpenter \& Linton, 2016), and online affinity spaces (Nacu, Martin, Pinkard, \& Gray, 2016) have sought to honor educator curiosity and amplify the affordances of new technologies as relevant to everyday problems of practice (see also Nussbaum-Beach \& Hall, 2012; Smith, West-Puckett, Cantrill, \& Zamora, 2016). These emerging approaches to educator learning highlight the limitations of routinized and formally sanctioned professional development, and further disrupt assumptions about how time and space bound hybrid learning environments and practices.

We contend that open approaches to web annotation can create conditions that mediate educator agency in reference to sociopolitical texts and contexts, and that participation in such everyday media practice is consequential to educator learning. Our chapter shares an affinity with scholars who foreground the use of critical theory when studying digital media and educational technology (e.g., Facer, 2011; Friesen, 2013; Garcia et al., 2015). Furthermore, we draw upon an approach to inquiry that engages multiple stakeholders in participatory design research for the sake of educational and social transformation (e.g., Gutiérrez et al., 2017; Taylor \& Hall, 2013). Our scholarly influences and methodological commitments also align with an ethos of openness evidenced by the transformative potential of open education movements (Deimann \& Peters, 2016; Seely Brown \& Adler, 2008), the proliferation of open educational resources (OER) and practices (OEP; Havemann, 2016), and everyday expressions of openly networked and interest-driven learning (Carfagna, 2014). The dialogic practices of web annotation, and in particular 
OWA, are germane to the examination and amplification of educator agency that is responsive to both political and pedagogical contexts.

In this chapter, we advance three interrelated goals. First, we introduce annotation and conceptualize intertextuality to describe how web annotation creates dialogic spaces which gather together people and texts, coordinates expression and meaning-making, and attends to political agency. Second, we introduce a social design experiment organized around a collaborative OWA effort - the Marginal Syllabus - that sought to create the conditions for educator participation in political conversation about educational equity. Third, we present a case study selected from the inaugural year of the Marginal Syllabus (201617). By utilizing a mixed method approach to data collection, analysis, and the presentation of findings, we examine open data as learning analytics and also conduct discourse analysis to describe how OWA mediated educator participation among sociopolitical texts and contexts of professional relevance. Our chapter concludes with discussion pertinent to future research, including recognition that the sociotechnical affordances of OWA are a promising means of architecting educator participation - and encouraging political dialogue - in open learning environments.

\section{BACKGROUND: TEXT, CONTEXT, AND INTERTEXTUALITY}

Annotation may be defined as the addition of new information to a source text, and is commonly associated with book marginalia, text highlights, and written notation, whether for the purposes of personal study or as a form of conversation between reader and author. From the scholia associated with Homer's Iliad (Snipes, 1988) to the "mutivalent" qualities of Talmudic commentary (Phelps \& Wilensky, 1996), annotation has notable historical roots that precede our digital era; in Medieval literary cultures, for example, annotated texts "served as a public resource for sharing information" (Wolfe \& Neuwirth, 2001, p. 334). Within more contemporary contexts saturated by digital texts and technologies, the social and technical practices of annotation were an important influence when Tim Berners-Lee (1989) first proposed an architecture for what has become today's internet. In his seminal Information Management: A Proposal, Berners-Lee emphasized the role of annotation in information accessibility, project documentation, and linked resources. With the advent of hypertext, Berners-Lee envisioned how the relationship between document and information could be transformed via "hot spots," such as:

“...icons, or highlighted phrases, as sensitive areas. touching [sic] a hot spot with a mouse brings up the relevant information, or expands the text on the screen to include it. Imagine, then, the references in this document, all being associated with the network address of the thing to which they referred, so that while reading this document you could skip to them with a click of the mouse" (para. 22).

Today, it is no longer necessary to imagine such associations; "hot spots," "highlighted phrases," and linked information are now taken for granted features of everyday digital environments, whether in mainstream news media, Wikipedia, or openly accessible scholarship. Accordingly, it is perhaps unsurprising that web annotation technologies and practices are flourishing across varied contexts, including scholarly publication and peer review (Stains, 2017a, 2017b), journalism (Cillizza, 2015), legal education (Miller \& Loren, 2015), and scientific research (Perkel, 2015).

When a student jots equations in the margins of a textbook (Marshall, 1997) or scholars use a web-based system to collaborate atop a manuscript (Zaugg, West, Tateishi, \& Randall, 2011), a connection is established among source, scribble, and circumstance. In this respect, annotation may be understood as mediating linkages between text and context (Marshall \& Brush, 2004), establishing texts-as-contexts for collaborative activity. If, as Luke (1996) suggests, all "texts are located in key social institutions: families, schools, churches, workplaces, mass media, government, and so on" (p. 13), then the everyday media 
expressions of annotation - as well as new media palimpsests produced by annotating - flourish among and help to sustain texts-as-contexts. As researchers who study learning as socially situated participation among communities and cultural contexts (e.g., Greeno, 1997; Lave \& Wenger, 1991), so, too, does our approach to the study of annotation "require a theorization and description of both the social processes and structures which give rise to the production of a text, and of the social structures and processes within which individuals or groups as social historical subjects, create meanings in their interaction with texts" (Wodak, 2001, p. 3). We perceive annotation as a social process, we consider web annotation communityoriented technology (Wenger, 2001) mediated by social structures, and - in this chapter - we study educator collaboration and learning across texts-as-contexts. Specifically, we report both designs for and analyses of educator learning via OWA, and explore how the social and collaborative practices of OWA created meanings connected to political and professional texts-as-contexts.

So as to theorize the referential, dynamic, and collaborative qualities of texts-as-contexts, we draw upon the concept of intertextuality to explicate the social and technical practices afforded by web annotation. There is no singular definition of intertextuality and the term broadly concerns reference to and juxtaposition among multiple texts by individuals during communication (Allen, 2011; Bloome \& EganRobertson, 1993). Perspectives on intertextuality are frequently traced to Bakhtin's (1981) assertion that all language is dialogical, meaning that written and spoken language is always in dialogue with other texts and authors. Furthermore, if what people write and say is responsive to and connected with other documents, ideas, and people, then language is both socially situated and constructed. With historic and paper-based annotation practices reimagined and extended "as a new layer of interactivity and linking on top of the Web" (Web Annotation Working Group, 2017, par. 1; see also Kalir \& Dean, 2018; Schacht, 2015), we contend that intertextuality is a germane conceptual perspective for the study of educator collaboration, learning, and political agency when such activity is situated among multiple sociopolitical texts-as-contexts.

Studies about digital media and learning across formal and informal environments have regularly featured Bakhtian interpretations of intertextuality (e.g., Davies \& Merchant, 2007; Gee, 2004; Kumpulainen \& Sefton-Green, 2014; Leander \& McKim, 2003). For example, in Kumpulainen and Sefton-Green's (2014) survey of conceptual heuristics that expand notions of learning across space and time, they suggest intertextuality emphasizes "the social construction of relationships among contexts past, present, and future. Across time and events, a consequential progression shapes texts, practices, and knowledges" (p. 14). As distinguishable from studies of digital media artifacts like video games or fan fiction, which can evidence intertextual qualities (Gee, 2003; Jenkins, 2006), we suggest the social activities of web annotation are inherently intertextual practices. From such an intertextual stance, annotation has been characterized as a "rich cultural practice" (Brown \& Duguid, 1996) with expansive qualities that gather together people, their texts, and interpretive meaning so as to "underwrite" and "coordinate" social practices across multiple related contexts. Following Brown and Duguid's (1996) observation that annotation coordinates social and collaborative practices, consider a reader who marks up an online text, highlighting phrases, commenting upon an argument, or linking information to related evidence. In this case, her annotation marshals a distributed information ecology of people, technologies, and values (Nardi \& O’Day, 1999) that are connected to a broader constellation of contexts, whether interest-driven, professionally-relevant, or responsive to political commitments.

The intertextual quality of web annotation is further apparent when considering advances in OWA. As described by Kalir and Dean (2018), both the defining characteristics and associated learning practices of OWA bolster dialogic collaboration within and across texts-as-contexts. OWA is defined, first and foremost, by an interoperable data model that allows annotations to be shared among projects and across technologies (Web Annotation Working Group, 2017). Such openness ensures that web annotation, as a form of open data, is portable across digital spaces and also over time. OWA is also distinguished by the ability for annotations to be publicly accessible through Creative Commons licensing, contributing to a 
participatory knowledge commons that favors networked peer communities and a "digital logic" of openness (Deimann \& Peters, 2016). Furthermore, OWA aligns with a variety of open movements, including those associated with open-source software (Lessig, 1998) and open educational practices (Havemann, 2016). Consider, for instance, the intertextual qualities apparent in the open science initiative Climate Feedback (Revkin, 2016). Climate Feedback demonstrates how a distributed network of experts utilize OWA to coordinate collaboration across varied texts-as-contexts: volunteer climate scientists publicly peer review journalism about climate change using OWA; these scientists connect texts published in the press with empirical scholarship; scientists then assess the validity of news media via evidence-based "feedbacks;" and public summaries about both individual news articles and media organizations are framed by discourses about the value of scientific accuracy and everyday scientific literacy. While intertextuality may not be a defining feature of OWA, OWA practices buoy a repertoire of social and technical practices that encourage the dialogic interactions characteristic of intertextuality.

When conceptualized as intertextual activity, OWA also recalls Wegerif's (2007) exploration of dialogic space as relevant to expansive and participatory educational technology practices. Wegerif's approach to the design and analysis of learning technology advocates a "dialogic alternative" that frames technology as a tool "opening up" new spaces for thinking, learning, and even play. Dialogic space, according to Wegerif, opens up when, under certain circumstances, "two or more perspectives are held together in tension" (p. 4). The presence of multiple author and reader perspectives held together in tension by annotation appears, for example, in Hollett and Kalir's (2017) study of playgrids, or emergent configurations of collaborative media practices and technologies that curate pathways for interest-driven learning. Annotation, in their case, subverted the limitations of online commentary and also coordinated improvisational dialogues atop texts-as-contexts (see also Kalir \& Dean, 2018). For Schacht (2015), annotation functions as a form of "writing-as-conversation," and "typically begins by gesturing toward an actual or hypothetical position taken by another" (par. 8). This literature, alongside related research (e.g., Jones, 2015), demonstrates how texts represent authorial perspective with reader annotation illustrating a second, and at times divergent, perspective. It is annotation, as both media and mediation, that opens up dialogic space between author and reader; annotating holds both perspectives together in an intertextual tension.

Our conceptualization of OWA as intertextual activity also suggests a potential for sociotechnical practice to foster political dimensions of discourse. The act of annotation is a nexus for matters of permission and consent, authority and power - whether or not annotation content is expressly political. Notably, the OWA technology featured in this chapter, Hypothesis, was created as a means of speaking truth to power. Annotation, from this stance, is conceived as an additive social and technical practice by which everyday citizens can contribute their voice to various texts and contexts. As discussed by Kalir and Dean (2018): "The idea is there are all these official voices on the web and everyday people need a way to join that conversation... we're not just accessing knowledge on the internet, but creating it ourselves. But it's not at all the way the web has evolved in terms of the everyday ability to effectively question authority, both technically and politically" (p. 25). Recent research about learning technologies has detailed how the use of particular tools, within designed learning environments, can encourage political dimensions of talk, even when such "talk" primarily comprises digital writing. Slakmon and Schwarz's (2017) study of online argumentative discussion found that "computerized tools that materialize discussions may function as promoters of political education... [virtual] space becomes a place in which students exercise power over each other. They assert political agency, practice power, and produce spaces of appearance" (p. 214). In this chapter, we are interested in how political dimensions of discourse emerged through the public interactions of OWA, and how educators who participated in such collaborative activity asserted political agency in reference to and across sociopolitical texts-as-contexts. Specifically, this chapter addresses two broad research questions. First, how can OWA organize activity in a political project oriented toward educational equity? Second, how can educators exercise political agency through OWA, and what might these political dimensions of annotation conversation and collaboration look like? 


\section{THE MARGINAL SYLLABUS AS SOCIAL DESIGN EXPERIMENT}

Within the field of education, a growing body of research has primarily examined web annotation in relation to students' reading comprehension, critical thinking, and the development of domain-specific knowledge (e.g., Johnson, Archibald, \& Tenenbaum, 2010; McNutt, 2014; Novak, Razzouk, \& Johnson, 2012; Su, Yang, Hwang, \& Zhang, 2010). This literature, broadly, adopts an instrumentalist stance, presenting and positioning web annotation as an innovative means by which to pursue conventional goals of formal schooling. Moreover, much of this research features methodological approaches whereby researchers adopt traditional roles - designing interventions, observing trials, and measuring effects - all while remaining distanced from the people, social relations, and complexities of human activity that arise through annotation. As a point of contrast to this research trend, our methodological commitments to the study of web annotation are inspired by advances in both design-based research (Barab \& Squire, 2004) and practitioner inquiry (Cochran-Smith \& Lytle, 2009) that couple researchers together with participants in the co-construction of theoretically-robust activity that is directed toward educational change. In particular, we embrace our deep entanglement with an expressly political project that is "organized around the development of an equity-oriented, humanist research agenda" (Gutiérrez \& Vossoughi, 2010, p. 102).

The broader OWA effort described in this chapter, and our case study of educators' intertextual activity in OWA conversation, draws upon the first year of a burgeoning social design experiment (Gutiérrez \& Jurow, 2016). According to Gutiérrez and Vossoughi (2010), social design experiments are a "democratizing form of inquiry" which aim to create open and expansive learning systems demonstrating "transformative potential." Our social design experiment is organized around the Marginal Syllabus, a project that utilizes OWA to convene and sustain conversations with educators about equity in education (http://marginalsyllab.us; see also Kalir, 2018). On a monthly basis, educators participating in the Marginal Syllabus read and openly annotate a digital text contributed by a partner author. From one month to the next, OWA conversations are layered atop the collection of Marginal Syllabus texts, with dialogue distinguished by educators actively questioning and critiquing issues of equity in teaching and learning.

The project name, Marginal Syllabus, embraces multiple political and technical interpretations of the term marginal. First, marginal refers to texts and perspectives that are counternarratives (e.g., Bullough, 2008; Milner, 2007) to dominant educational discourses and values. Second, marginal also indicates the location of OWA conversation and collaboration in the margins of online texts-as-contexts. And third, educator learning is mediated by an open-source technology (Hypothesis) that is marginal to commercial educational technology. Launched in August of 2016, the Marginal Syllabus has grown into a partnership co-constructed by various stakeholders, including: K-12 classroom teachers and administrators; authors and publishers who contribute texts for annotation; the non-profit organization Hypothesis, an organization that has built an influential open-source web annotation technology (Whaley, 2017); the National Writing Project, a premier literacy education organization in the United States that provides professional development across all levels of education; and university-based education researchers. The Marginal Syllabus is neither affiliated with partisan affairs nor a specific cause; rather, we describe the effort as a political project because it leverages OWA as a mediator of professional learning for educators who are eager to co-author critical conversations about educational equity across sociopolitical texts-ascontexts.

Marginal Syllabus stakeholders have attended carefully, though at times not without conflict, to the design principles of re-mediation, contradiction, historicity, and equity that collectively distinguish social 
design experiments as a methodology (Gutiérrez \& Vossoughi, 2010). First, because OWA situates social discourse both within and also among multiple texts as authentic dialogic contexts, the Marginal Syllabus attempts to re-mediate educator learning across robust and expansive learning ecologies. Through Marginal Syllabus participation, the re-mediation of educator learning is stretched across novel technical and ideational tools, social relations, and professionally-relevant resources. Second, as Marginal Syllabus organizers, we have also sought to anticipate and constructively work with inevitable contradiction.

During the Marginal Syllabus' inaugural year, "stress points" arose in association with conflicts posed by open access to digital content and also author consent to have texts annotated. Third, social design experiments must be responsive to "people's history of involvement with the valued practices of their communities and the routine activities of everyday life" (Gutiérrez \& Vossoughi, 2010, p. 103). For Marginal Syllabus participants, OWA is approached as an everyday media practice related to information literacy, as well as access to and authorship of digital texts (Kalir \& Dean, 2018). Moreover, Marginal Syllabus conversations are predicated upon a historicized understanding of the valued - and often contested - practices of schooling and learning. For participating teachers, OWA is a means of making sense of, and if necessary critiquing, the social, cultural, and historical practices of formal education. Fourth and finally, the sociotechnical affordance of OWA are distinctively supportive of a requirement in social design experiments to develop and document "equity trails" (Gutiérrez \& Vossoughi, 2010). Because (web) annotation creates networks of "associative trails" across documents, knowledges, and contexts (Bush, 1945), it is possible to trace equity-oriented developments at various scales of the project; as a theme among syllabus texts, as central to partnership decision-making, and as expressed in the dialogue of participating educators. As of this writing (July, 2018), the Marginal Syllabus is commencing its third year of programming. As a dynamic social design experiment, Marginal Syllabus organizers, facilitators, and researchers are committed to exploring how OWA bolsters an expressly political project. We are documenting how educator participation in OWA encourages political aspects of dialogue, and interrogating how equity is both conceptualized and operationalized in all facets of this public initiative.

Our case study draws upon one of nine Marginal Syllabus conversations facilitated during the project's first year (August, 2016 through May, 2017). As noted, these OWA conversations were organized in consultation with partner authors and situated within a text contributed by authors. As key project stakeholders, the ten partner authors included two K-12 teachers, seven higher education professors, and one independent scholar. The nine texts in the 2016-17 syllabus addressed topics such as digital redlining and information accessibility (Gilliard \& Culik, 2016), curriculum co-design (Zamora, 2015), culturally relevant pedagogy (Emdin, 2017), the politics of educational technology (Beetham, 2016), critical literacy (Garcia \& O'Donnell-Allen, 2015), and personal narrative (LeMay, 2016), among others (for a full list of texts and topics visit http://bit.ly/marginalsyllabus1617). Six of the ten partner authors also annotated alongside dozens of educators who participated in at least one of the nine OWA conversations. The selection of a single conversation from the 2016-17 Marginal Syllabus may be perceived as a limitation of the case study presented in this chapter. However, doing so allowed members of our research team to strategically experiment with mixed method approaches (Tashakkori \& Teddlie, 2010) to the collection, analysis, and visualization of open data, which we now describe in detail.

\section{COLLECTING, ANALYZING, AND VISUALIZING OPEN DATA}

This case study examines the very first Marginal Syllabus conversation, which commenced in August, 2016, to describe how OWA organized educator activity in a political project positioned toward educational equity, and to suggest how the intertextual qualities of OWA mediated political aspects of educator dialogue. The conversation was organized around the reading and annotation of Digital Redlining, Access, and Privacy (Gilliard \& Culik, 2016), a blog post featured on the reputable website Common Sense Education (Figure 1, below). The concept of digital redlining is an intertextual reference to America's history of discriminatory financial practices that resulted in segregated housing and 
"redlined" neighborhoods (Coates, 2014). In their post, Gilliard and Culik (2016) explain how acceptable use and internet privacy policies create digital redlines, or inequitable educational opportunities for students. They also discuss how digital redlining policies may differ according to institution or context by comparing information accessibility for students attending research-intensive universities to community colleges.

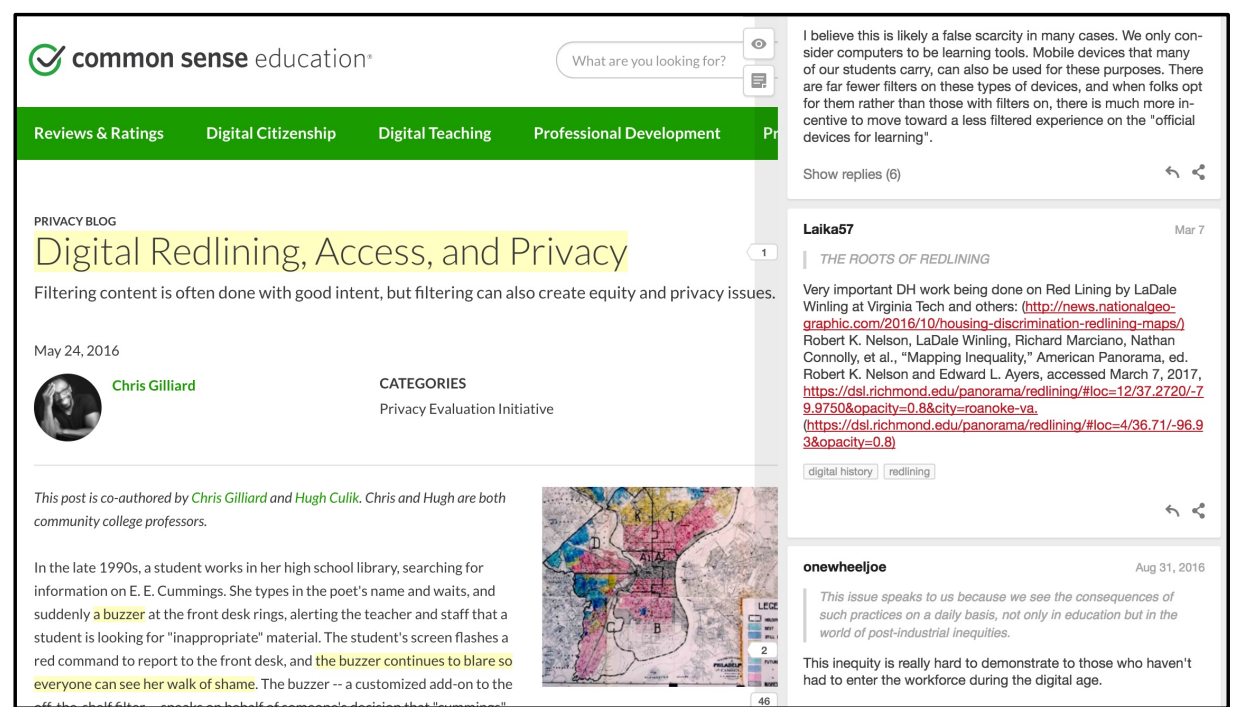

Figure 1. Blog post about digital redlining and internet accessibility contributed by partner author Chris Gilliard, showing selection of highlighted text and corresponding Hypothesis annotations

As noted, defining characteristics of OWA include annotations created according to an interoperable data model, and also Creative Commons licensing of all public annotations. This means that it was possible for our research team to collect, analyze, and visualize a corpus of open data associated with the 190 public annotations authored by 17 educators, as well as our partner author (Gilliard) and the first author of this chapter (Kalir), all of whom used Hypothesis during this Marginal Syllabus conversation.

How were educators collaborating with one another during this conversation? What were they discussing? And what were the political qualities of educator dialogue when OWA mediated conversation? To engage these questions, we adopted mixed method approaches to collecting, analyzing, and visualizing open data from this particular conversation about digital redlining, informational accessibility, and privacy. Working with Hypothesis open data meant selecting methods appropriate to analyzing the content of annotations; that is, what an educator wrote as the substance of her annotation or commented as a reply to another annotation. Additionally, Hypothesis open data allowed us to study annotation metadata, including who authored an annotation or reply, the digital text which anchored new annotation content, a timestamp, any descriptive tags, the inclusion of media or hyperlinks, and possible parent-child relationships (i.e. replies to original annotations). Both forms of open data - annotation content and annotation metadata - afforded us two distinct yet complementary ways of advancing our case study.

In the first phase of our analysis, we examined OWA metadata as learning analytics (Perez \& Kalir, 2018). We identified three different types of learning analytics; descriptive statistics, social networks, and kernel density estimations were all means of studying Marginal Syllabus participants as learners and online texts as learning contexts "for the purposes of understanding and optimizing learning and the environments in which it occurs" (Siemens, 2012, p. 4). The first phase of our analysis echoed other digital media and learning researchers who have examined open data and online interaction as forms of learning analytics (Gruzd, Paulin, \& Haythornthwaite, 2016; Shum \& Ferguson, 2012). The second phase of our analysis applied discourse analysis methods to a selection of annotation content. We utilized three 
"theoretical tools" (Gee, 2011) - situated meaning, social language, and intertextuality - to identify political dimensions of discourse evident in educators' Marginal Syllabus conversation. Together, both learning analytics and discourse analysis methods allowed us to study how OWA mediated educator learning among, and in reference to, sociopolitical texts-as-contexts.

\section{Analyzing OWA Metadata as Learning Analytics}

The first phase of our data analysis was primarily quantitative and automated. To analyze the Marginal Syllabus conversation which started in August, 2016, we collected OWA metadata from the Hypothesis application program interface (API). Our analysis was performed on the Jupyter platform using the Python programming language and the pandas library (pandas is an open-source library that structures data for analysis and visualization). Because Python is a general purpose programming language, we were able to build the ancillary workflows needed to collect, format, and visualize annotation metadata as a form of learning analytic (e.g., Gruzd, Paulin, \& Haythornthwaite, 2016). These steps were packaged into a single Jupyter notebook and automated to identify descriptive statistics, conduct social network analysis (SNA), and create kernel density estimation (KDE) visualizations. Together, these three analytic methods provided insight about who participated in the Marginal Syllabus conversation, how educators collaborated with one another, and how OWA organized shared activity.'

Descriptive statistics. First, we created graphs visualizing metadata associated with educator participation in the focal conversation, including stacked bar graphs and time series line graphs. Figure 2 (below) is a quantitative summary of educators' total in-line annotations (i.e. reader-to-text annotation) and replies (i.e. reader-to-reader annotation). Figure 3 illustrates the conversation's temporal progression, tracking when educators contributed their annotations.

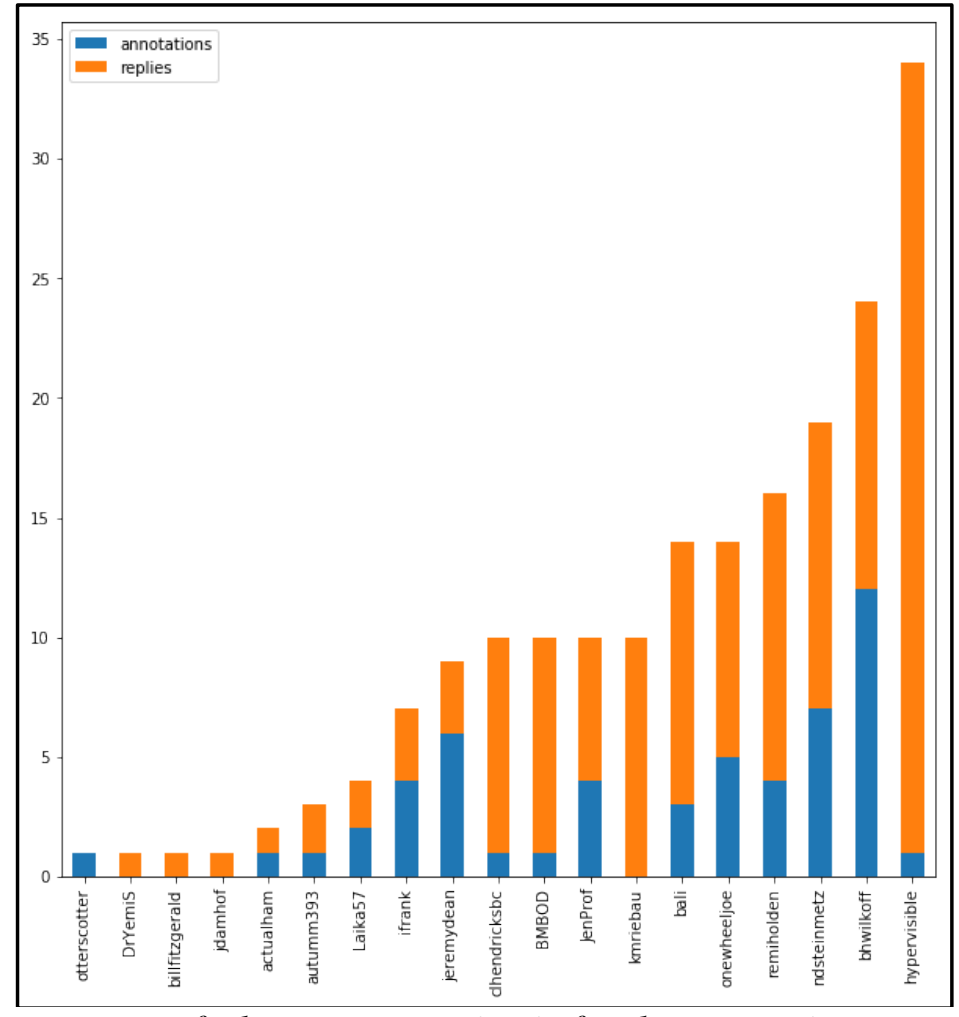

Figure 2. Quantitative summary of educator annotation in focal conversation 


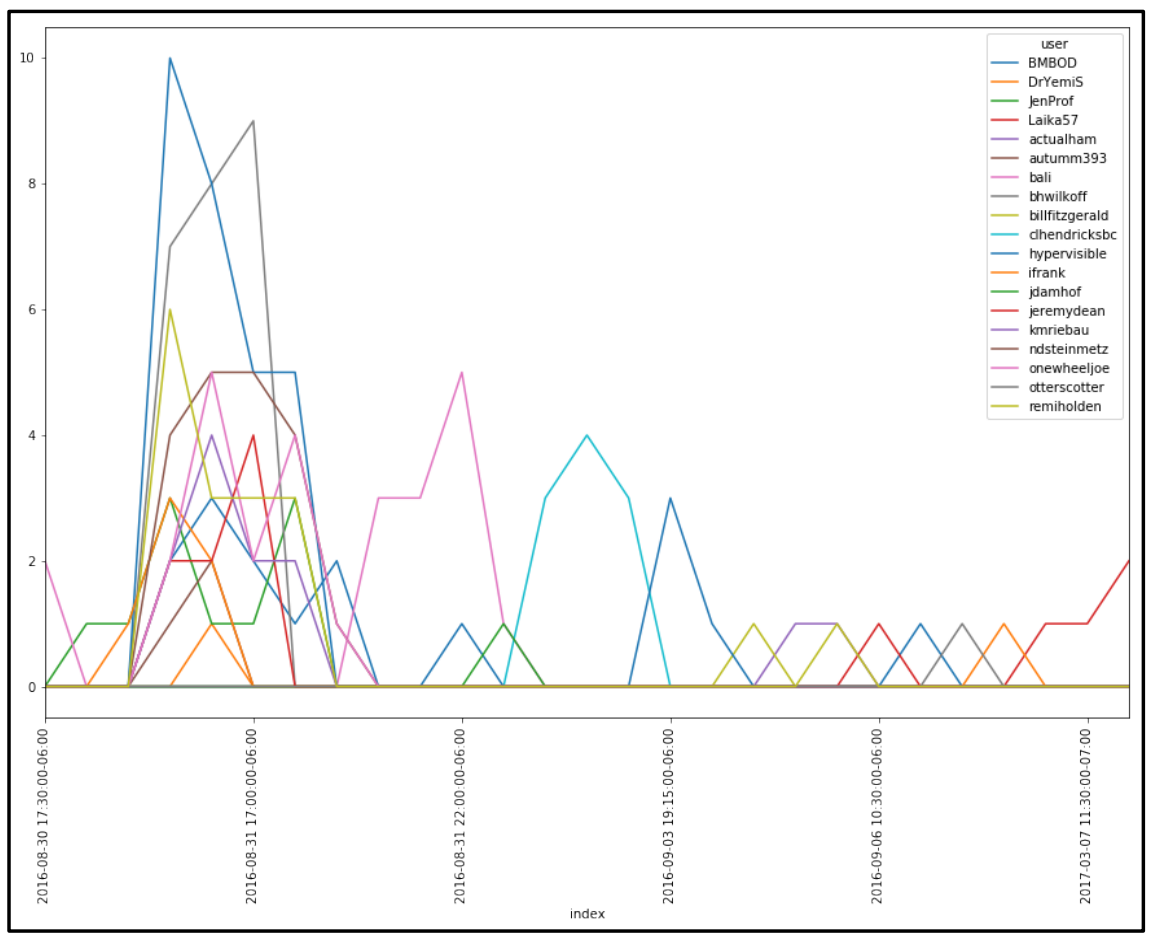

Figure 3. Timestamp analysis of educator participation in annotation conversation

Of the 190 total annotations, $72 \%$ (137 of 190) were replies, suggesting annotation primarily mediated social interaction among participants. Our partner author, Gilliard (who annotated via the handle "hypervisible"), contributed 33 replies, or nearly one quarter of all replies. More than half the participants (10 of 19) contributed at least 10 annotations (either in-line annotations or replies), accounting for 161 of the total 190 annotations (85\% of the dataset), suggesting a majority of participating educators were highly engaged discussants. As for the temporal qualities of the conversation, timestamp metadata illustrates that while most annotation was concentrated during a single hour in late August (per our initial activity design), contributions were regularly added into early September, with a few annotations added in March of 2017.

Social network analysis (SNA). Second, we utilized Onodo, an open-source SNA visualization tool, to further understand how educators interacted with one another, the partner author, and the author's text during conversation. We represented participants and the text as nodes (circles), and annotations as directed edges (arrows). SNA illustrated how interactions among groups of participants structured OWA conversation. Figure 4 is a network representation that parsed all 190 Hypothesis annotation records for metadata associated with "sender," or the participating educator, and "destination," either an in-line annotation of the focal text or a reply to another annotation. 


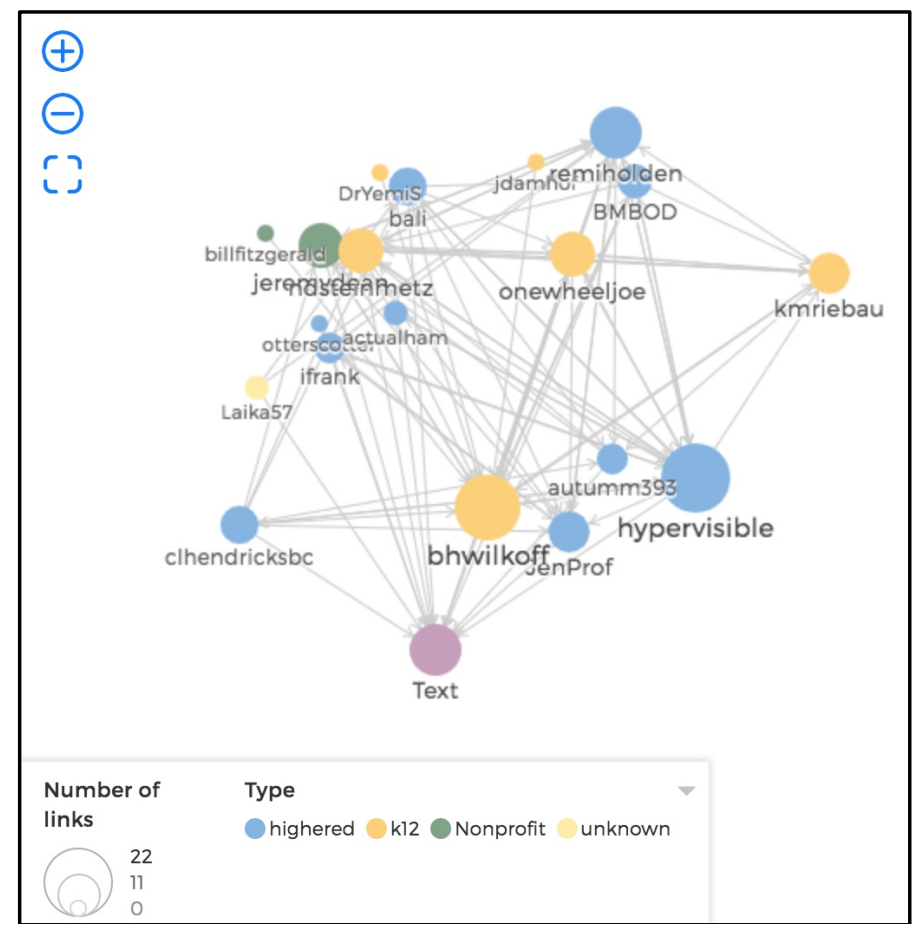

Figure 4. Social network analysis visualizing educator interactions during OWA conversation

Figure 4 illustrates reader-to-reader, reader-to-author, and reader-to-text OWA relations via SNA. Participants are represented as nodes, with node size corresponding to the educator's overall annotation volume (mirroring descriptive statistics reported in Table 2). Nodes are also color-coded according to the educator's affiliation; K-12 educators are dark yellow, higher education faculty are blue; non-profit educators are green; and the text is purple. This SNA representation indicates three discursive clusters among participants, all of which crossed institutional affiliations (i.e. K-12 and higher education). This clustering suggests educators privileged bi-directional reader-to-reader collaboration over independent and unidirectional reader-to-text annotation.

Kernel density estimation (KDE). The third way in which we analyzed Hypothesis metadata as learning analytics was through the production of visual "heatmaps" (e.g., Bigham \& Murray, 2010). These maps identified where, within the focal text, educators concentrated their OWA collaboration. Figure 5 and Figure 6 are two KDE visualizations that identified areas in the focal text where educators' OWA conversation was most concentrated; that is, where the greatest density of their annotation occurred over time (for a related example of social media data analyzed via KDE for heatmap visualization see Kumar, Morstatter, \& Liu, 2014). 


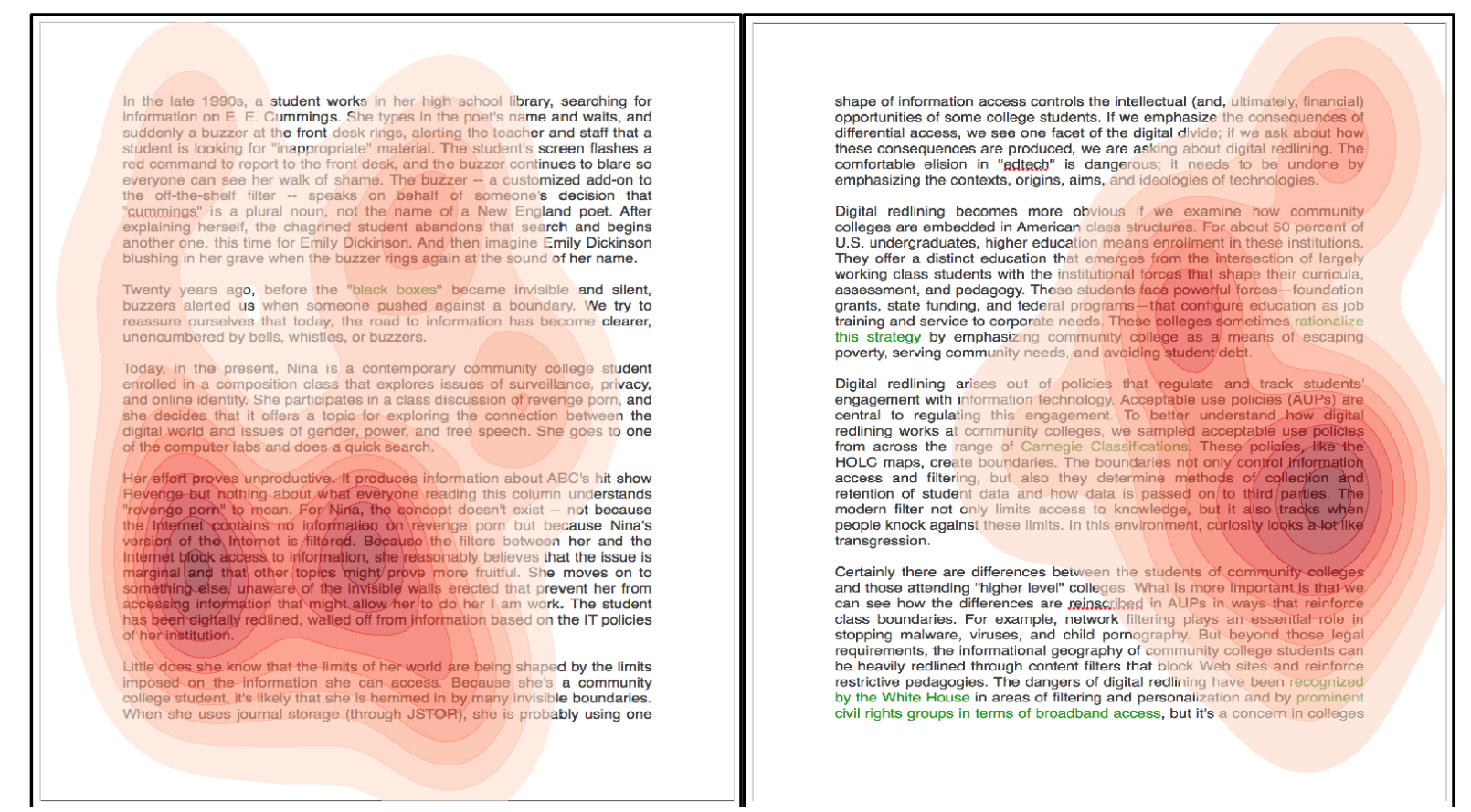

Figures 5 and 6. Sample KDE visualizations identifying locations of dense OWA conversation

As a spatial approach to analysis, KDE helped us to pinpoint the three densest locations of OWA conversation, thereby guiding where we would subsequently focus discourse analysis of annotation content (as described in the next section). Rather than randomly select annotations for an analysis of what educators discussed, KDE allowed us to filter the corpus of 190 annotations down to three excerpts totaling 27 annotations, or approximately $15 \%$ of the dataset.

\section{Analyzing OWA Content via Discourse Analysis}

The second phase of our data analysis was qualitative and inductive. KDE identified areas of the focal text where educator conversation was most concentrated. Annotation content from the three densest areas was collected and organized into excerpts; Excerpt 1 included 12 annotations authored by nine participants; Excerpt 2 included six annotations authored by five participants; and Excerpt 3 included nine annotations authored by five participants. Thirteen of the 19 total participants contributed either annotations or replies to these excerpts. Having selected and organized annotation content for analysis, we then applied the "theoretical" discourse analysis tools of situated meaning, social language, and intertextuality $(\mathrm{Gee}, 2011)$ to examine in detail political elements of dialogue present in educators' OWA conversation.

Situated meaning. The use of a word or phrase can take on different meanings in different contexts. This is what Gee (2011) suggests when he describes the meaning of words as "situated." Whether spoken or written (via annotation), words will have "different and specific meanings in different contexts in which they are used and in different specialist domains that recruit them" (p. 152). All 27 annotations comprising the three excerpts were analyzed to identify situated meanings associated with words or phrases in educators' conversation. For example, the phrase "digital redlining" took on various meanings in this annotation from the first excerpt:

JenProf: "Of course. So we can make the case that we are digitally manipulated. But is every filter a red line? Don't want to get off track here, but I think there are distinctions. This article addresses redlining at the institutional level." 
In the context of JenProf's annotation, digital redlining was an action related to individuals ("we") being "manipulated." More specifically, digital redlining was related to how "institutional level" practices limited an individual's digital activity or access to information. For JenProf, the situated meaning of this phrase also referred to some type of information filter ("red line" as a noun), yet the characteristics of such digital redlining could be questioned and are also variable ("there are distinctions"). Our approach to this aspect of discourse analysis allowed us to discern political meanings attributed to words and phrases in the context of a conversation about information accessibility, filtering, and privacy.

Social language. Social language, according to Gee (2011), are styles of language (whether spoken or written) that are enacted and associated with a specific social identity. Educators, we suggest, will use a given social language when speaking with colleagues about aspects of their professional lives, like pedagogy or the use of technology. The social language of educators will also vary depending upon discipline, whether they work in K-12 or post-secondary settings, or due to other distinguishing aspects of identity. As such, the discourse of a speaker or writer "acts out a particular type of who - a particular social identity - the speaker must also make clear what he or she is doing, what action or activity, appropriate to that identity, he or she is carrying out" (p. 157). While it is accurate that educators participated in the Marginal Syllabus, this descriptor ("educators") is not entirely sufficient for the purposes of analysis given the use of social language throughout the focal conversation, as evidenced in this annotation from Excerpt 2:

bhwilkoff: "I think it may be important to ask whether analytics and tracking are the same as filtering. While I would argue against both in some cases, the knowledge of the interest of your patrons/users may in fact create better policies and not worse."

Here, bhwilkoff used the social language of a technology administrator ("patrons/users") to argue ("in fact") in favor of actions appropriate to that social identity, namely to "create better policies and not worse." The three excerpts were analyzed to identify social language, variations in social language that reflected differing social identities among educators, and how social language indicated political aspects of conversation.

Intertextuality. Given this study's conceptual orientation toward OWA as intertextual activity in textsas-contexts, it was appropriate that our third approach to discourse analysis utilized Gee's (2011) intertextuality tool. Intertextuality, within the scope of this method, can refer to: quotes, direct references, or allusions to other texts (including various forms of media); text which incorporates the social language or identity of another text; and text which incorporates grammar or structure associated with the social language of another text. An annotation that evidenced intertextuality includes the following criticism about learning management systems (LMS) from Excerpt 3:

onewheeljoe: “And the 'walled garden' shelters learners - instructors and students alike from a great deal."

onewheeljoe's reference to the "walled garden" is frequently used to discuss proprietary and closed technology platforms. Moreover, the term has been historically associated with the development of educational technologies like the LMS (Bull \& Hammond, 2008), as well as with more critical commentaries about learning technology (e.g., Beasley, 2012). As with the previously detailed discourse analysis methods, all three conversation excerpts were analyzed to identify various forms of intertextuality, with careful attention given to educator references or allusions that indicated political dimensions of their dialogue. 


\section{EDUCATOR POLITICAL DISCOURSE IN OWA}

In this section we present three examples of educator conversation mediated by OWA, with a focus on describing political dimensions of discourse elicited by Marginal Syllabus participants. Each excerpt begins by identifying anchor text, or the selection from Gilliard and Culik (2016), that was highlighted by a reader and used to anchor their Hypothesis annotation. Every annotation or reply in an excerpt is presented as an utterance within the conversation's turns of talk. All annotations feature the following details: An alphanumeric code and indentation to designate the hierarchy of dialogue within the parentchild tree structure of communication; the participant's Hypothesis handle (in italics), the annotation content, and a timestamp (in Eastern Standard Time) to provide a sense of discursive pace over time (see also Figure 3). Following each excerpt, we share findings that synthesize insight from both phases of our data analysis to substantiate claims about the political dimensions of educator dialogue, as well as the qualities of educator collaboration that occurred within and referenced sociopolitical texts-as-contexts.

\section{Excerpt 1: Scrutinizing Digital Redlining as Filtering}

The first excerpt of educator OWA conversation (Text Box 1, below) occurred atop an observation by Gilliard and Culik (2016), made toward the beginning of their blog post, about digital redlining as a filter of content that inhibits information accessibility. The author's presented a realistic scenario in which a community college student attempted to conduct research online, via a computer in her school's library, about the controversial topic of revenge pornography. Her effort proved unsuccessful as she "has been digitally redlined, walled off from information based on the IT [information technology] policies of her institution" (par. 4).

Text Box 1. Educator OWA conversation that scrutinized digital redlining as filtering (Excerpt 1)

Anchor text: "Because the filters between her and the Internet block access to information,"

1 jeremydean: Not to derail this great discussion, but Isn't the Internet already a filter? We need to teach students that even Google is always already filtered... [08/31/2016 18:34]

1A kmriebau: yeah, it makes me think about the prevalence of "echo chambers" and our awareness of being in one or not... [08/31/2016 18:36]

1B JenProf: Of course. So we can make the case that we are digitally manipulated. But is every filter a red line? Don't want to get off track here, but I think there are distinctions. This article addresses redlining at the institutional level. [08/31/2016 18:38]

1B1 ndsteinmetz: Also brings about the question "should there be filters"? Are they necessary? At any level? [08/31/2016 18:44]

1B2 hypervisible: Right. A big part of why we wrote this is having taught at other institutions, we see the very different ideas about access. Also, when college access is the main access (or only access) it matters more. That's where the redlining happens. [08/31/2016 18:50]

1C hypervisible: Totally, and it's really important to convey that, but the institutional filter is layered on top of that. [08/31/2016 18:44] 
1D autumm393: So, could the problem be not so much the filter itself as the illusion that there is no filter? Sure we can't ever escape the filters because there is just so much information the only way to consume it is to filter it. If you don't understand that there are filters and if you don't understand what filters there are then you are prime for manipulation. [08/31/2016 18:46]

1D1 kmriebau: Yes, my thought exactly! Everything is filtered somehow. We have to understand how our own brain filters the world all the way to how information is presented to us by whom. Critical thinking needs to be the new norm. [08/31/2016 18:56]

1D2 bali: I think you're right Autumm. And as others are saying... The commercial drive behind filtering of Google; the redlining behind filtering on campuses...how and why these filters work that way and how they restrict our access to knowledge [09/01/2016 00:07]

1D3 clhendricksbc: I completely agree. Where can we find the information useful to show students what is being filtered and how, in various situations? The problem sometimes is that that information may be hard to get. What is the algorithm Google uses? Facebook? Other things? Sometimes these are hard to find. Anyone have any good resources for giving students concrete examples of what is filtered and how by these popular services? [09/03/2016 16:21]

1D3A hypervisible: I'm not sure any exist at this time. I'm actually interested in doing a crowdsourced project that might show what diff results show up at different institutions. There are some slight variations that you could get by using a VPN and changing your location. [09/03/2016 21:19]

1E onewheeljoe: I think the commercial aspects of the Internet are important to think critically about with youth. We can help them understand the profit motives of the companies who provide web access. Only by understanding the why can we deepen the conversation. [08/31/2016 19:11]

In this excerpt of OWA conversation, the phrase digital redlining and the word filter convey varied intertextual qualities and situated meanings that draw upon multiple historic, political, and social contexts. As noted, redlining refers to a painful history of American financial and housing practice that intentionally segregated everyday physical places, like neighborhoods; digital redlining alludes to this history in order to describe contemporary social and technical practices that inequitably partition everyday digital spaces. The word filter also references a contested history that includes the federal Children's Internet Protection Act (Federal Communications Commission, 2017), free speech litigation by groups like the American Library Association (ALA Office for Intellectual Freedom, 2000), and ongoing debate about information accessibility in public settings such as libraries (Caldwell-Stone, 2013). Complementing these references, this excerpt reveals nine educators scrutinizing digital redlining as a form of filter, including what filtering means in educational contexts, what information is filtered under certain circumstances, and who has power to control filtering practices. The situated meaning of digital redlining as filtering varies according to ideas about echo chambers (1A), manipulation (1B, 1D), and algorithms (1D3). The meaning of filtering is also closely associated with power, including the power and "profit motives of the companies who provide web access" (1E), like Google (1, 1D2, 1D3), as well as educational institutions (i.e. 1B, 1B2) to control filters that position individuals as "prime for 
manipulation" (1D). In this conversation, educators have recruited a range of contextual associations to convey how digital redlining and filter are sociotechnical practices situated among physical and digital settings (i.e. libraries, classrooms, online), and that these practices operate according to institutional and corporate power across these contexts.

As an expression of agency that resists how digital redlining "restrict[s] our access to knowledge" (1D2), participants in this excerpt annotated with multiple social languages that reflect different social identities. These social identities included: educator who teaches with technology (i.e. 1B2, 1D3, 1E), technology critic (i.e. 1, 1D, 1D2, 1E), and information consumer (i.e. 1A, 1D). That some of these social identities overlapped suggests that educator OWA also evidenced heteroglossia (Bakhtin, 1981), or multiple varieties of "voice" within a given language or text. For Gee (2011), heteroglossia "interleaves two different social languages" (p. 161) and indicates the presence of multiple social identities. Excerpt 1 includes multiple annotations whereby participants wove together two social identities, like educator who teaches with technology and educator who is critical of technology. For example, clhendricksbc (1D3) affirmed pedagogical responsibility as an educator who uses technology to examine filtering practices ("to show students what is being filtered"), and also inquired ("Anyone have good resources...") about whether others might support future critical inquiry about technology ("...what is filtered and how by these popular services?"). Additional annotations by bali (1D2), hypervisible (1D3A), and onewheeljoe (1E) evidence similar heteroglossic discourse at the intersection of educational technology user and educational technology critic. Among these varied and, at times, intersecting social identities, educators' pedagogical and ethical scrutiny of digital redlining as filtering signified a critical quality throughout their OWA conversation.

\section{Excerpt 2: Debating Terminology, Texts, and Agency}

The second excerpt of educators' OWA conversation (Text Box 2, below) accompanied a section of Gilliard and Culik's (2016) post that summarized their previous efforts studying acceptable use policies (AUPs) at higher education institutions. The authors report upon an analysis of 30 AUPs "to better understand how digital redlining works at community colleges" (par. 10), and to emphasize the inequitable differences associated with internet filtering and information accessibility which exist between community colleges and research-intensive universities.

Text Box 2. Educator OWA conversation that debated terminology, texts, and agency (Excerpt 2)

Anchor text: "The modern filter not only limits access to knowledge, but it also tracks when people knock against these limits. In this environment, curiosity looks a lot like transgression."

1 bhwilkoff: I think it may be important to ask whether analytics and tracking are the same as filtering. While I would argue against both in some cases, the knowledge of the interest of your patrons/users may in fact create better policies and not worse. [08/31/2016 18:41]

1A BMBOD: This makes me think of the government sponsored hackathons, code breaking competitions, etc. You identify individuals that can push against the boundaries and limits, and then proposition them to make the next round of boundaries. It's a reflexive practice that perpetuates itself. [08/31/2016 18:52]

1A1 bhwilkoff: Maybe. But, I have seen many organizations use analytics to better serve their users and not find ways to better restrict. [08/31/2016 19:07] 
1B billfitzgerald: While analytics and tracking are obviously different activities than filtering, they are connected and mutually supportive. Understanding how they work together is a critical element to interrogating and pushing back against uses that disempower individuals. Give the widespread use (and opacity of that use) of tracking and analytics to power filtering, the onus is on people who want to use these technologies to demonstrate that they can use them responsibly. [09/05/2016 14:59]

2 ndsteinmetz: It may always look this way, isn't that what freedom of thought has traditionally been labeled? New ideas and innovation seem to be a threat in many cases. [08/31/2016 18:59]

3 bali: Powerful statement. And I agree it can apply to some conservative classrooms and some general policy/attitude beyond the digital [08/31/2016 23:46]

In Excerpt 2, five educators anchored their annotations atop a statement about the technical affordances and social implications of internet filters. Analysis of situated meaning and social identity suggest the ensuing conversation raised many questions: How are tracking and analytics related to filtering? What qualities of agency are associated with different types of people, and with different technologies? Is freedom of thought transgressive? As a point of contrast to Excerpt 1, this selection of conversation solicited three separate in-line annotations by three educators, all of which were anchored to commentary about the power of internet filters to track online activity. Also unlike Excerpt 1, educators actively debated with one another, providing divergent viewpoints about opportunities and limitations associated with controversial sociotechnical practices. The meaning of words like filtering, tracking, and analytics varied according to social identity and specialist activity, such as technology administrator (i.e. bhwilkoff) and technology critic (i.e. billfitzgerald). In the former instance, these terms were connected to a sense of managerial agency, to "create better policies and not worse" (1). In the latter, the words evoked a sense of agency as collective and critical responsibility, of "pushing back against uses that disempower individuals" (1B). Across all six annotations in this excerpt, the coupling of filtering, tracking, and analytics with the government (1A), power and responsibility (1B), "freedom of thought" (2), and "conservative classrooms" (3) indicate educators' political stance toward discussing how people's use of the internet is filtered, and why such filtering should be managed or resisted.

Excerpt 2 also includes multiple annotations that feature intertextual allusions to technologies as either types of texts or as implicated in the creation of texts. In some annotations, references were made to digital texts, including both analytics $(1,1 \mathrm{~A} 1,1 \mathrm{~B})$ and also code $(1 \mathrm{~A})$. In other annotations, educators connected the use of a technology, like filters, to the creation of a governance text, namely policy $(1,3)$. For educators, analytics, code, and policy were forms of text connected to contexts where power is exercised in differential ways. For example, analytics appear in organizations (1A1) whereby the use of these technologies, whether surreptitiously or benevolently, can identify "the interest of your patrons/users" (1). Alternatively, the use of analytics in other organizational contexts may "power filtering" and "disempower individuals" (1B). Code, as another type of digital text, was mentioned when referencing "government" contexts and state-sponsored competitions, like "hackathons," that allow people to "push against the boundaries and limits" (1A) of powerful technologies.

For many educators in this discussion, the ways in which technologies-as-texts were deployed across professional, pedagogical, and political contexts suggested varied interpretations of agency in the face of power. ndsteinmetz advocated for individual "freedom of thought," which may be perceived as "a threat in many cases" (2). bali agreed that curiosity can manifest as transgression in both "conservative classrooms" and other settings "beyond the digital" (3). This selection of discourse was distinguished by educators debating when, how, and why "pushing back against [technology] uses that disempower 
individuals" (1B) can be justified. The five educators featured in this excerpt demonstrated that technologies may be discussed as types of texts connected to contexts, and that debate about power, agency, and the use of such technology in varied contexts remains unresolved.

\section{Excerpt 3: Questioning Educational Designs}

The final OWA excerpt featured five participants, including the partner author and first author of this chapter (Text Box 3, below). Located toward the blog post's conclusion, the participants engaged with a suggestion by Gilliard and Culik (2016) that in order to "critique" digital redlining and institutional technology policy, it was necessary "to begin by asking questions about the implicit pedagogy of any technology we are looking to adopt" (par. 16).

Text Box 3. Educator OWA conversation that questioned educational designs (Excerpt 3)

Anchor text: "Does it restrict or promote openness and access?"

1 remiholden: In my experience with most LMSs, there is an implicit pedagogy that does restrict openness and co-production and sharing of knowledge and information. In this respect, digital redlining is packaged as efficiency, classroom management, etc. [08/31/2016 18:55]

1A hypervisible: YEP! [08/31/2016 23:25]

1B JenProf: Agreed. Because the LMS also manages grades, calendars, etc., students (and profs) experience these as part of a pedagogical design. [08/31/2016 19:26]

1B1 remiholden: Particularly now, as a graduate-level educator, the presence of the grade book in an LMS reinforces this idea that I'm an accountant. Ugh. [08/31/2016 19:27]

1B1A onewheeljoe: And the "walled garden" shelters learners - instructors and students alike - from a great deal. [08/31/2016 19:36]

2 ndsteinmetz: This should be the driving question of all EdTech and IT departments of educational institutions! [08/31/2016 19:13]

2A remiholden: Agreed, these are very powerful questions! And perhaps I'd add: And in promoting greater openness and access, how do our tools and processes create the conditions for greater educational equity? [08/31/2016 19:23]

2A1 onewheeljoe: What skills and fluencies are we trying to develop? [08/31/2016 19:27]

2A1A ndsteinmetz: What opportunities are we providing for skills and fluencies to develop? Are they filtered or open so that fluencies and skills can be maieutic at their core? [08/31/2016 19:31]

Excerpt 3, like the second, featured multiple in-line annotations (by remiholden and ndsteinmetz), both of which generated responses from three other participants. Similar to Excerpt 1, many of these participants drew upon a range of social identities to engage a question about how technologies, like the LMS, and 
organizations, such as "IT departments" (2), are - or are not - responsive to issues of accessibility and openness. When discussing constraints of the LMS, educators used specialist language to indicate their social identities as experts who teach with technology, as when JenProf noted that the LMS "manages grades, calendars, etc... as part of a pedagogical design" (1B). Educators like onewheeljoe also used distinct social language to position themselves as insiders who can criticize that same technology: "The 'walled garden' shelters learners... from a great deal" (1B1A). Heteroglossic qualities also appeared in this exchange, as JenProf and onewheeljoe suggested educators are learners who experience technologies in ways similar to students (i.e. lack of openness), blending together voices that were instructional and critical. In contrast to commentary, from other excerpts, about "giving students concrete examples" (Excerpt 1: 1D3) or observing how technology has been used in "some conservative classrooms" (Excerpt 2: 3), these annotations by JenProf and onewheeljoe were distinguished by empathy; the constraints of certain technologies can be disaffecting for everyone, "instructors and students alike" (1B1A). These educators' public and empathic affinity with student experience may be interpreted as a political gesture given accounts of instructor-student relations as either adversarial or apathetic.

Perhaps because Excerpt 3 was anchored to an evaluative question about whether a given technology restricts information accessibility and promotes openness, educator contributions to this conversation included detailed inquiries about educational designs. Aside from an affirming "YEP!" (1A), the educators featured in this excerpt voiced concern about the social and technical aspects of various educational designs. As discussed, JenProf explicitly interrogated the "pedagogical design" (1B) of the LMS, and onewheeljoe included an intertextual reference to historical critiques of the technology. Educators also asked questions about how to craft their pedagogy (2A1), how to develop students' skills and fluencies (2A1,2A1A), and how to shape the priorities of education departments and organizations (2). For ndsteinmetz, the tendency to question educational designs also elicited reference to a Socratic form of inquiry: "Are they [technology] filtered or open so that fluencies and skills can be maieutic at their core?" (2A1A). Questions about the design of technology, pedagogy, and instruction also echoed previous observations about educators' agency and their ability to influence learning technologies and environments. This agentic leadership was captured by both onewheeljoe and ndsteinmetz, whose exchange about "the driving question of all EdTech and IT departments" (2) was grounded in shared recognition that it is "we" (2A1, 2A1A) who are responsible for envisioning and fostering more accessible and open learning opportunities and outcomes. From critiques of the "walled garden" to inquiry about leadership, educators questioned a variety of educational designs in this excerpt, and they did so by referencing contexts imbued with pedagogical and political relations.

\section{DISCUSSION AND FUTURE RESEARCH DIRECTIONS}

Our discussion considers future research directions related to the broader commitments of this research agenda, specifically: Conceptualizing OWA as intertextual activity within and across texts-as-contexts; advocating for OWA as a means of mediating educator professional development as positioned toward inquiry and change; using multiple methods for the analysis of OWA data generated by educators; and identifying the sociotechnical affordances of OWA to architect educator learning, collaboration, and participation in political dimensions of talk.

This case study drew conceptual inspiration from Bakhtin's (1981) assertion that all language is dialogical. Approaching (web) annotation as a written form of public dialogue, we studied the Marginal Syllabus' OWA activities as socially situated among various relationships - with partner authors, atop their texts, and in reference to pedagogical and political contexts mentioned by participating educators. In contrast to research that considers annotation a type of instructional intervention (e.g., Novak et al., 2012), our decision to conceptualize OWA as intertextual activity allowed us to examine how Marginal Syllabus conversation opened dialogic space (Wegerif, 2007), or a space of tension between two or more 
perspectives. Our discourse analysis of three excerpts from the first Marginal Syllabus conversation evidenced multiple and, at times, conflicting perspectives. OWA authored by participating educators functioned like digital signposts, tracing the emergent tensions of dialogic space between individual agency and institutional policy, or among the social identities of technology user, technology administrator, and technology critic. While it is productive for annotation studies to focus upon individuals and discrete skills (e.g., reading comprehension; see Johnson et al., 2010), we argue it is equally generative to shift the scale of inquiry toward social, collaborative, and even conflicting activity. We also contend that future research should foreground the intertextual and "mutivalent" (Phelps \& Wilenwky, 1996) qualities of annotation as a mediator of collaboration among texts-as-contexts. Whether in their discussions of classrooms, technologies, or institutions, educator participation in Marginal Syllabus conversation was simultaneously rooted in and directed toward political and pedagogical settings. An intertextual and dialogic approach to the study of annotation allowed us to identify and analyze how OWA elicited debate about the contested meaning of terms, texts, and contexts.

Just as it was possible to conceptualize OWA as intertextual activity, so too was it important that we detail how OWA mediated a public educational effort concerned with both inquiry and social change. OWA played a central role in orchestrating collaborative activity in the Marginal Syllabus as a social design experiment (Gutiérrez \& Vossoughi, 2010), or a type of participatory design research that adopted an expansive and equity-oriented approach to the study of learning. Influenced by other social design experiments that have studied how learning technologies organize and propel inquiry across settings (e.g., Taylor \& Hall, 2013), our effort leveraged open-source technology (Hypothesis) and open educational practices as a means of coordinating educator discussion across and in reference to multiple sociopolitical texts-as-contexts. As an everyday media practice with political origin and import (Kalir \& Dean, 2018), we suggest our study demonstrates the importance of researching how OWA can mediate open learning environments for educators whereby annotation conversation is simultaneously collaborative, constructive, and also critical. The sociotechnical affordances of OWA helped shape educators' Marginal Syllabus conversation as an opportunity, for example, to critique instructional technologies and to question educational designs, including those associated with their own institutions. While many educators use social media to participate in public and professionally-relevant conversation (like Twitter chats; see Carpenter \& Krutka, 2015), the political dimensions of those discussions are seldom explicit or encouraged. As one response, we designed and described the Marginal Syllabus as a political project challenging dominant models of professional development that too frequently stifle educator voice. Additionally, our effort relied upon open-source technology and everyday media practices to amplify educator interest about - and agency within - conversations explicitly concerned with educational equity.

From a methodological perspective, it was also important that our research used mixed methods to collect, analyze, and visualize open data to describe how OWA coordinated educator collaboration in the Marginal Syllabus as a public and political project. We worked with open data in a number of distinctive ways that may be relevant to other researchers who consider open data a form of open educational resource that should be easily accessible and applicable to the public good (Atenas \& Havemann, 2015). First, we used Hypothesis OWA metadata to collect, report, and visualize learning analytics. Our goal in analyzing this metadata was to create a workflow that could be automated and recursive, given that annotation conversation occurred across different texts, with different participants, and at different intensities over time. Second, we committed to using free, open-source tools to more flexibly format, visualize, and share learning analytics via descriptive statistics, network analysis, and KDE. Our use of open-source software to analyze data from an open-source technology was intentional given the political and equity-oriented stance of this research project. Third, while content analysis methods can describe some features of online "communal textual discourse" (Gruzd et al., 2016), we embraced more semantically nuanced and situated discourse analysis methods (Gee, 2011) to discern how educators' annotation content evidenced political dimensions of talk in Marginal Syllabus conversation. As illustrated by our use of KDE to identify areas of subsequent discourse analysis, our approach synthesized 
quantitative and automated analysis of open metadata with qualitative and inductive analysis of educator's public discourse. We are hopeful that our methodological decisions resonate with other scholars whose research interests in (web) annotation, digital forms of communication, and open data require similarly creative - and mixed - methods of data collection, analysis, and visualization.

Finally, our case study of educator participation in the Marginal Syllabus suggests OWA may be a promising means of architecting public and professionally-relevant learning opportunities that amplify political dimensions of talk. Educators in this particular conversation routinely referenced multiple sociopolitical texts-as-contexts while using OWA to open dialogic space about digital redlining and information accessibility. We are cognizant of the need for more "politically aware" (Selwyn \& Facer, 2013) studies of learning technology, and strongly assert the centrality of educator voice in co-designing and shaping such conversation. That is why we grounded the Marginal Syllabus in Hypothesis web annotation; the technology has low barriers for entry and high standards for ethical online interaction, including both intellectual property protections and Creative Commons licensing that benefit the public knowledge commons. As a tool that encourages everyday citizens - like educators - to speak truth to power (Kalir \& Dean, 2018), we are heartened that the expressions of OWA conversation afforded by Hypothesis engender a type of publicly accessible "intellectual commons [which] shifts emphasis towards recognition that knowledge and its value are ultimately rooted in social relations, a kind of knowledge socialism that promotes the sociality of knowledge by providing mechanisms for a truly free exchange of ideas" (Peters, 2014, p. 5). Nonetheless, the design principles guiding this social design experiment demand greater articulation as this project grows, encounters contradiction, and interrogates commitments to both equity in conversational content and the processes of partnership. In our future research, we endeavor to move from identifying how OWA can architect educator professional learning (Kalir, 2018) toward identifying OWA design practices that robustly sustain educator political dimensions of talk and strengthen the ways in which such dialogue informs everyday teaching and learning practices.

\section{CONCLUSION}

This chapter described how open approaches to web annotation mediated educator participation in dialogic spaces that referenced, and were relevant to, multiple classroom and sociopolitical texts-ascontexts. We demonstrated how the Marginal Syllabus - a multistakeholder partnership among educators, authors and publishers, university researchers, Hypothesis, and the National Writing Project - enacted an open learning environment whereby K-12 and post-secondary educators added their voice to critical conversations about educational equity. The Marginal Syllabus, as a political project oriented toward both scholarly inquiry and social change, created public, low-barrier, and consequential opportunities for educators to question dominant narratives about school and envision more participatory and equitable learning opportunities. Using mixed methods for the collection, analysis, and visualization of open data from Hypothesis OWA, we detailed how annotation practices were used to underwrite and coordinate (Brown \& Duguid, 1996) educators' interest-driven and professionally-relevant learning. We presented and analyzed three excerpts from one Marginal Syllabus conversation to indicate how educators expressed forms of agency and critique in their public discourse, including through reference to multiple sociopolitical texts-as-contexts. Our case study suggests that educators who participated in the dialogic annotation activities of a social design experiment created intertextual references across texts-as-contexts when scrutinizing and debating sociotechnical terminology, expressing forms of agency associated with different social identities, and questioning educational designs. Despite debate and ambiguity about what counts as educator learning, and where and how such activity should occur, we assert that open approaches to the collaborative use of web annotation can spark the emergence of learning designs that blur entrenched distinctions between educators' formal learning and everyday media practice, as well as between professional and political relevance. 


\section{ACKNOWLEDGMENT}

This research was supported by a University of Colorado Denver School of Education and Human Development Faculty Development Grant. We are thankful for all the educators who participated in the 2016-17 Marginal Syllabus and, in particular, those featured in this chapter: hypervisible, autumm393, bali, kmriebau, JenProf, ndsteinmetz, clhendricksbc, bhwilkoff, BMBOD, billfitzgerald, onewheeljoe, and jeremydean. And we would be remiss not to express a special note of thanks to Christina Cantrill, Liana Gamber-Thompson, Tanya Baker, Joe Dillon, and Jeremy Dean for their leadership organizing and sustaining the Marginal Syllabus. Finally, thank you to the anonymous reviewers of this manuscript for their valuable feedback and scholarly guidance during the peer review process.

\section{REFERENCES}

ALA Office for Intellectual Freedom. (2000). Statement on Library Use of Filtering Software. Retrieved October 2, 2017, from http://www .ala.org/Template.cfm?Section=IF_Resolutions\&Template=/ContentManagement/Co ntentDisplay.cfm\&ContentID $=13090$

Allen, G. (2011). Intertextuality. New York, NY: Routledge.

Apple, M. W. (1995). Education and power (2nd ed.). New York, NY: Routledge.

Atenas, J., \& Havemann, L. (2015). Open Data as open educational resources: Case studies of emerging practice. London, UK: Open Knowledge, Open Education Working Group.

Bakhtin, M. (1981). The dialogic imagination. Four essays by M. M. Bakhtin. Austin: University of Texas Press.

Barab, S., \& Squire, K. (2004). Design-based research: Putting a stake in the ground. Journal of the Learning Sciences, 13(1), 1-14.

Beasley, W. (2012). Infiltrating the walled garden. Hybrid Pedagogy. Retrieved October 2, 2017, from http://www.digitalpedagogylab.com/hybridped/infiltrating-the-walled-garden/

Beetham, H. (2016). Ed tech and the circus of unreason. Retrieved October 2, 2017, from https://helenbeetham.com/2016/11/14/ed-tech-and-the-circus-of-unreason/

Berners-Lee, T. (1989). Information Management: A Proposal. Retrieved October 2, 2017, from https://www.w3.org/History/1989/proposal.html

Bigham, J. P., \& Murray, K. (2010). WebTrax: Visualizing non-visual web interactions. In International Conference on Computers for Handicapped Persons (pp. 346-353). Berlin, Germany: Springer. 
Bloome, D., \& Egan-Robertson, A. (1993). The social construction of intertextuality in classroom reading and writing lessons. Reading Research Quarterly, 28(4), 305-333.

Brown, J. S., \& Duguid, P. (1996). The social life of documents. First Monday, 1(1).

Bull, G., \& Hammond, T. (2008). The future of E-Learning in schools. In H. Adelsberger, J. Pawlowski, \& D. Sampson (Eds.), Handbook on Information Technologies for Education and Training (pp. 345-361). New York, NY: Springer.

Bullough, R. V. (2008). Counternarratives: Studies of teacher education and becoming and being a teacher. Albany, NY: SUNY Press.

Bush, V. (1945). As we may think. The Atlantic Monthly, 176(1), 101-108.

Caldwell-Stone, D. (2013). Filtering and the First Amendment. American Libraries, 44(3/4), 5861 .

Carfagna, L. (2014). Beyond learning-as-usual: Connected learning among open learners. Irvine, CA: Digital Media and Learning Research Hub.

Carpenter, J. P., \& Krutka, D. G. (2015). Engagement through microblogging: Educator professional development via Twitter. Professional Development in Education, 41(4), 707-728.

Carpenter, J. P., \& Linton, J. N. (2016). Edcamp unconferences: Educators' perspectives on an untraditional professional learning experience. Teaching and Teacher Education, 57, 97-108.

Cillizza, C. (2015, October 7). How annotation can save journalism. The Washington Post. Retrieved October 2, 2017, from https://www.washingtonpost.com/news/thefix/wp/2015/10/07/why-i-believe-annotation-is-the-future-of-journalism/

Coates, T. (2014, ). The case for reparations. The Atlantic. Retrieved October 2, 2017 from https://www .theatlantic.com/magazine/archive/2014/06/the-case-for-reparations/361631/

Cochran-Smith, M., \& Lytle, S. L. (2009). Inquiry as stance: Practitioner research for the next generation. New York, NY: Teachers College Press.

Cuban, L. (1986). Teachers and machines: The classroom use of technology since 1920. New York, NY: Teachers College Press.

Davies, J., \& Merchant, G. (2007). Looking from the inside out: Academic blogging as new literacy. In M. Knobel \& C. Lankshear (Eds.), A New Literacies Sampler (pp. 167-197). New York, NY: Peter Lang.

Deimann \& Peters. (2016). The philosophy of open learning: Peer learning and the intellectual commons. New York, NY: Peter Lang. 
Emdin, C. (2017). For white folks who teach in the hood... and the rest of y'all too: Reality pedagogy and urban education. Boston, MA: Beacon Press.

Facer, K. (2011). Learning futures: Education, technology and social change. New York, NY: Routledge.

Federal Communications Commission. (2017, September 08). Children's Internet Protection Act (CIPA). Retrieved October 2, 2017, from https://www.fcc.gov/consumers/guides/childrensinternet-protection-act

Friesen, N. (2013). Educational technology and the "new language of learning:" Lineage and limitations. In N. Selwyn \& K. Facer (Eds.), The politics of education and technology: Conflicts, controversies, and connections (pp. 21-38). New York, NY: Palgrave Macmillan.

Garcia, A., \& O'Donnell-Allen, C. (2015). Pose, wobble, flow: A culturally proactive approach to literacy instruction. New York, NY: Teachers College Press.

García, A., Mirra, N., Morrell, E., Martínez, A., \& Scorza, D. A. (2015). The council of youth research: Critical literacy and civic agency in the digital age. Reading \& Writing Quarterly, 31(2), 151-167.

Gee, J. P. (2003). What video games have to teach us about learning and literacy. Computers in Entertainment (CIE), 1(1), 20-20.

Gee, J. P. (2004). Situated language and learning: A critique of traditional schooling. New York, NY: Routledge.

Gee, J. P. (2011). How to do discourse analysis: A toolkit. New York, NY: Routledge.

Gilliard, C., \& Culik, H. (2016). Digital redlining, access, and privacy. Retrieved from https://www.commonsense.org/education/privacy/blog/digital-redlining-access-privacy

Gover, E. (2017, January 23). How social media enhances teacher professional development: Interviews with experts. Retrieved October 2, 2017, from https://rossieronline.usc.edu/blog/teacher-interviews-social-media/

Greeno, J. G. (1997). On claims that answer the wrong questions. Educational Researcher, 26(1), 5-17.

Gruzd, A., Paulin, D., \& Haythornthwaite, C. (2016). Analyzing social media and learning through content and social network analysis: A faceted methodological approach. Journal of Learning Analytics, 3(3), 46-71.

Gutiérrez, K. D., \& Jurow, A. S. (2016). Social design experiments: Toward equity by design. Journal of the Learning Sciences, 25(4), 565-598. 
Gutiérrez, K. D., \& Vossoughi, S. (2010). Lifting off the ground to return anew: Mediated praxis, transformative learning, and social design experiments. Journal of Teacher Education, 61(1-2), 100-117.

Gutiérrez, K. D., Cortes, K., Cortez, A., DiGiacomo, D., Higgs, J., Johnson, P., ... \& Vakil, S. (2017). Replacing representation with imagination: Finding ingenuity in everyday practices. Review of Research in Education, 41(1), 30-60.

Havemann, L. (2016). Open educational resources. In M. A. Peters (Ed.), Encyclopedia of Educational Philosophy and Theory. Singapore, Malaysia: Springer Singapore.

Hill, H. C. (2009). Fixing teacher professional development. Phi Delta Kappan, 90(7), 470-476.

Hine, C. (2015). Ethnography for the internet: Embedded, embodied and everyday. London, UK: Bloomsbury Publishing.

Hollett, T., \& Kalir. J. (2017). Mapping playgrids for learning across space, time, and scale. TechTrends, 61(3), 236-245.

Jenkins, H. (2006). Convergence culture: Where old and new media collide. New York, NY: NYU Press.

Johnson, T. E., Archibald, T. N., \& Tenenbaum, G. (2010). Individual and team annotation effects on students' reading comprehension, critical thinking, and meta-cognitive skills. Computers in Human Behavior, 26(6), 1496-1507.

Jones, J. (2014). There are no new directions in annotations. In J. Dougherty \& T. O’Donnell (Eds.), Web Writing: Why and How for Liberal Arts Teaching and Learning (pp. 263-274). Ann Arbor, MI: University of Michigan Press.

Jones, W. M., \& Dexter, S. (2014). How teachers learn: The roles of formal, informal, and independent learning. Educational Technology Research and Development, 62(3), 367-384.

Kalir, J. (2018). Bit, block, sketch, build: Bricolage and educator learning. Hybrid Pedagogy. Retrieved from http://hybridpedagogy.org/bit-block-sketch-build-bricolage/

Kalir \& Dean. (2018). Web annotation as conversation and interruption. Journal of Media Practice, 19(1), 18-29.

Kumar, S., Morstatter, F., \& Liu, H. (2014). Twitter Data Analytics. New York, NY: Springer.

Kumpulainen, K., \& Sefton-Green, J. (2014). What is connected learning and how to research it?. International Journal of Learning and Media, 4(2), 7-18.

Lankshear, C., \& Knobel, M. (2011). New literacies: Everyday practices and classroom learning. Maidenhead, UK: Open University Press. 
Lave, J., \& Wenger, E. (1991). Situated learning: Legitimate peripheral participation. Cambridge, UK: Cambridge University Press.

Leander, K. M., \& McKim, K. K. (2003). Tracing the everyday 'sitings' of adolescents on the internet: A strategic adaptation of ethnography across online and offline spaces. Education, Communication \& Information, 3(2), 211-240.

LeMay, M. (2016). Personal narrative, revised: Writing love and agency in the high school classroom. New York, NY: Teachers College Press.

Lessig, L. (1999). Open code and open societies: Values of Internet governance. Chicago-Kent Law Review. 74, 101-116.

Luke, A. (1996). Text and discourse in education: An introduction to critical discourse analysis. Review of Research in Education, 21(1), 3-48.

Marshall, C. C. (1997). Annotation: From paper books to the digital library. In R. Allen \& E. Rasmussen (Eds.), Proceedings of the second ACM international conference on Digital libraries (pp. 131-140). Philadelphia, PA: ACM.

Marshall, C. C., \& Brush, A. B. (2004). Exploring the relationship between personal and public annotations. In H. Chen, H. Wactlar, \& C. Chen (Eds.), Proceedings of the 2004 Joint ACM/IEEE Conference (pp. 349-357). Tuscon, AZ: ACM/IEEE.

Miller, J. \& Loren, L. (2015). The idea of the casebook: Pedagogy, prestige, and trusty platforms. Washington Journal of Law Technology \& Arts, 11(31), 31-48.

Milner IV, H. R. (2007). Race, culture, and researcher positionality: Working through dangers seen, unseen, and unforeseen. Educational Researcher, 36(7), 388-400.

McNutt, M. (2014). More science in the classroom. Science, 346(6212), 895-895.

Nacu, D. C., Martin, C. K., Pinkard, N., \& Gray, T. (2016). Analyzing educators' online interactions: A framework of online learning support roles. Learning, Media and Technology, 41(2), 283-305.

Nardi, B. A., \& O’Day, V. (1999). Information ecologies: Using technology with heart. Cambridge, MA: MIT Press.

Novak, E., Razzouk, R., \& Johnson, T. E. (2012). The educational use of social annotation tools in higher education: A literature review. The Internet and Higher Education, 15(1), 39-49.

Nussbaum-Beach, S., \& Hall, L. R. (2012). The connected educator: Learning and leading in a digital age. Bloomington, IN: Solution Tree Press. 
Perez, F., \& Kalir, J. (2018). Open web annotation as connected conversation in CSCL. In J. Kalir (Ed.), Proceedings of 2018 Connected Learning Summit. Pittsburgh, PA: ETC Press.

Perkel, J. (2015). Annotating the scholarly web. Nature 528(7580), 153-154.

Peters, M. A. (2014). Openness and the intellectual commons. Open Review of Educational Research, 1(1), 1-7.

Pew Internet \& American Life Project (2013). How teachers are using technology at home and in their classrooms. Washington, DC: Purcell, K., Heaps, A., Buchanan, J., \& Friedrich, L.

Phelps, T. A., \& Wilensky, R. (1996). Multivalent documents: Inducing structure and behaviors in online digital documents. In H. El-Rewini \& B. Shriver (Eds.), Proceedings of the TwentyNinth Hawaii International Conference on System Sciences, (Vol. 5, pp. 144-152). Wailea, HI: IEEE.

Revkin, A. (2016, May 3). Scientists build a hype detector for online climate news and commentary. The New York Times. Retrieved October 2, 2017, from https://dotearth.blogs.nytimes.com/2016/05/03/scientists-build-a-hype-detector-for-onlineclimate-news-and-commentary/

Schacht, P. (2015). Annotation. In MLA Commons Digital Pedagogy in the Humanities: Concepts, Models and Experiments. Retrieved October 2, 2017, from https://digitalpedagogy.mla.hcommons.org/keywords/annotation/

Seely Brown, J., \& Adler, R. P. (2008). Open education, the long tail, and learning 2.0. Educause Review, 43(1), 16-20.

Selwyn, N., \& Facer, K. (Eds.). (2013). The politics of education and technology: Conflicts, controversies, and connections. New York, NY: Palgrave Macmillan.

Shum, S. B., \& Ferguson, R. (2012). Social learning analytics. Journal of Educational Technology \& Society, 15(3), 3-26.

Siemens, G. (2012). Learning analytics: Envisioning a research discipline and a domain of practice. In S. Shum, D. Gasevic, \& R. Ferguson (Eds.), Proceedings of the 2nd International Conference on Learning Analytics and Knowledge (pp.4-8). Vancouver, Canada: ACM.

Slakmon, B., \& Schwarz, B. B. (2017). "Wherever you go, you will be a polis": Spatial practices and political education in computer-supported collaborative learning discussions. Journal of the Learning Sciences, 26(2), 184-225.

Smith, A., West-Puckett, S., Cantrill, C., \& Zamora, M. (2016). Remix as professional learning: Educators' iterative literacy practice in CLMOOC. Education Sciences, 6(1), 12. 
Snipes, K. (1988). Literary interpretation in the Homeric scholia: The similes of the Iliad. The American Journal of Philology, 109(2), 196-222.

Stains, H. (2017a, August 23). A new annotation capability: Publisher groups. Retrieved October 2, 2017, from https://web.hypothes.is/blog/publisher-groups/

Stains, H. (2017b, September 13). Making peer review more transparent with open annotation. Retrieved October 2, 2017, from https://web.hypothes.is/blog/transparent-peer-review/

Su, A. Y., Yang, S. J., Hwang, W. Y., \& Zhang, J. (2010). A Web 2.0-based collaborative annotation system for enhancing knowledge sharing in collaborative learning environments. Computers \& Education, 55(2), 752-766.

Taylor, K. H., \& Hall, R. (2013). Counter-mapping the neighborhood on bicycles: Mobilizing youth to reimagine the city. Technology, Knowledge and Learning, 18(1-2), 65-93.

Tashakkori, A. \& Teddlie, C. (2010). Handbook of mixed methods in social and behavioral research. London, UK: SAGE Publications.

Udell, J. (2017). Teaching students to marshall evidence and evaluate claims. EDUCAUSE Review, 52(2), 58-59.

Visser, R. D., Evering, L. C., \& Barrett, D. E. (2014). \#TwitterforTeachers: The implications of Twitter as a self-directed professional development tool for $\mathrm{K}-12$ teachers. Journal of Research on Technology in Education, 46(4), 396-413.

Watters, A. (2016). The curse of the monsters of educational technology. Retrieved October 2, 2017, from http://monsters3.hackeducation.com

Web Annotation Working Group. (2017). What are web annotations? In Web annotation working group. Retrieved October 2, 2017, from https://www.w3.org/annotation/

Webster-Wright, A. (2009). Reframing professional development through understanding authentic professional learning. Review of Educational Research, 79(2), 702-739.

Wegerif, R. (2007). Dialogic education and technology: Expanding the space of learning. New York, NY: Springer.

Wenger, E. (2001). Supporting communities of practice: A survey of community-oriented technologies. Retrieved October 2, 2017, from

https://guard.canberra.edu.au/opus/copyright_register/repository/53/153/01_03_CP_technology_ survey_v3.pdf

Whaley, D. (2017, February 24). Annotation is a now a web standard. Retrieved October 2, 2017, from https://hypothes.is/blog/annotation-is-now-a-web-standard/ 
Wodak, R. (2001). What CDA is about - a summary of its history, important concepts and its developments. In R. Wodak \& M. Meyer (Eds.), Methods of Critical Discourse Analysis (pp. 113). London, UK: SAGE Publications.

Wolfe, J. L., \& Neuwirth, C. M. (2001). From the margins to the center: The future of annotation. Journal of Business and Technical Communication, 15(3), 333-371.

Zamora, M. (2015). Speculative design for emergent learning: Taking risks. Retrieved October 2, 2017, from https://via.hypothes.is/https://dmlcentral.net/speculative-design-for-emergentlearning-taking-risks/

Zaugg, H., West, R. E., Tateishi, I., \& Randall, D. L. (2011). Mendeley: Creating communities of scholarly inquiry through research collaboration. TechTrends, 55(1), 32.

\section{KEY TERMS AND DEFINITIONS}

Annotation: The addition of new information to a source text, commonly associated with book marginalia, text highlights, and written notation.

Dialogic space: A discursive space of tension between two or more perspectives, such as that between a text author and annotator.

Digital Redlining: Contemporary social and technical practices, such as internet filtering, that partition everyday digital spaces and create inequitable learning opportunities.

Intertextuality: Reference to and/or juxtaposition among multiple texts by individuals during communication.

Marginal Syllabus: A project that utilizes open web annotation to convene and sustain conversations with educators about equity in education.

Open Learning: An approach to the design and facilitation of learning opportunities that are public and easily accessible, use open educational resources and practices, and encourage participation in a shared knowledge commons.

Open Web Annotation: A form of web annotation that relies upon an interoperable data model, generates publicly accessible data, supports Creative Commons licensing of annotation content, and aligns with open-source software and educational movements.

Text-as-context: The use of social and collaborative open web annotation to turn an online text into a participatory and discursive context.

\footnotetext{
' Analysis for this study was conducted in the fall of 2017 and does not reflect additional Hypothesis OWA subsequently contributed to the focal text and conversation by additional educators.
} 